\title{
Is endovascular stent grafting for descending thoracic aortic disease recommendable in patients with dysphagia?
}

\author{
Sidney Chocron, MD, PhD, ${ }^{a}$ Lucian Stoica, MD, ${ }^{a}$ Stephane Koch, MD, ${ }^{b}$ Jean-François Bonneville, MD, \\ Djamel Kaili, MD, ${ }^{a}$ Bruno Heyd, MD, PhD, ${ }^{d}$ and Joseph-Philippe Etievent, MD, ${ }^{a}$ Besançon, France.
}

$\mathrm{E}$ ndoluminal stent graft repair is an alternative to conventional surgical intervention. Perioperative complications associated with the endoluminal technique are arterial injury, maldeployment, aortic perforation, left upper limb ischemia, and paraplegia. Secondary complications are leaking, graft migration, aortoesophageal fistula, and aortobronchial fistula. ${ }^{1}$

There are various conditions associated with aortoesophageal fistula: foreign bodies, malignancy, primary fistula of thoracic aortic aneurysm, or secondary fistula after surgical repair of these aneurysms. ${ }^{2}$ We report 2 cases of an uncommon condition: aortoesophageal fistula after stenting of a descending thoracic aneurysm and of a spontaneous aortic rupture with a periaortic hematoma.

\section{Clinical Summary}

The first patient is a 79-year-old man whose medical history is limited to inguinal hernia repair. He presented with a persistent cough, left pulmonary hilar mass, progressive complete aphagia, and weight loss. Esophageal fiberoptic endoscopy revealed erosive lesions with alimentary residue in a midesophageal tumefaction area $30 \mathrm{~cm}$ from the dental arch. Biopsies were done and revealed nonspecific lesions. Computed tomographic (CT) scans performed for the left pulmonary hilar mass showed a 94-mm-diameter aortic aneurysm compressing the left main bronchus, the esophagus, and the left atrium (Figure 1). The aortogram showed a saccular aneurysm, $84 \mathrm{~mm}$ high and $94 \mathrm{~mm}$ wide in its largest portion, with a $30-\mathrm{mm}$ postsubclavian neck.

Because of the age and the general status of the patient, we opted for endovascular repair. The anatomy of the aneurysm and the aortoiliac arteries allowed the endovascular procedure.

A Talent endoluminal stent graft (World Medical Corp, Sunrise, Fla) was deployed through the right femoral artery. The cover part of the stent was $100 \mathrm{~mm}$ long and $34 \mathrm{~mm}$ wide. The proximal and distal edges of the graft were dilated with a $34-\mathrm{mm}$-diameter

From the Departments of Thoracic and Cardiovascular Surgery, ${ }^{a}$ Gastroenterology, ${ }^{\mathrm{b}}$ Radiology, ${ }^{\mathrm{c}}$ and Surgery, Transplant Unit, ${ }^{\mathrm{d}} \mathrm{J}$. Minjoz Hospital, Besançon, France.

Received for publication Feb 20, 2002; accepted for publication March 27, 2002.

Address for reprints: Sidney Chocron, MD, PhD, Department of Cardiac Surgery, J. Minjoz Hospital, Besançon, France 25030 (E-mail: chocron@ufc-chu.univ-fcomte.fr).

J Thorac Cardiovasc Surg 2002;124:1239-41

Copyright $\odot 2002$ by The American Association for Thoracic Surgery

$0022-5223 / 2002 \$ 35.00+0 \quad \mathbf{1 2 / 5 4 / 1 2 5 2 0 7}$

doi: $10.1067 / \mathrm{mtc} .2002 .125207$ balloon for better stent expansion and exclusion of the aneurysm. There was no leaking and no adverse event at the time of the procedure.

The patient started to eat 10 days later and was discharged on day 14. Forty-five days later, he returned with anemia and melena. Over this period, the patient had eaten normally and gained weight. Injected CT scanning showed no leak, no stent migration, and no kinking. The aneurysm decreased to $60 \mathrm{~mm}$ in its widest part (Figure 1). Esophageal fiberoptic endoscopy revealed an aortoesophageal fistula on the posterior part of the middle third of the esophagus with a tissue loss $50 \mathrm{~mm}$ high and $30 \mathrm{~mm}$ wide, which allowed us to view the superior part of the endoprothesis. Because the patient's condition precluded another operation, we proposed palliative treatment. The lack of substance was covered by an esophageal prosthesis, but the patient still required one packed red cell unit transfusion per day. Finally, we complied with the patient's request to stop treatment and send him home. He died 10 days later.

The second case is a 59-year-old woman with a medical history of arterial hypertension, obesity, and smoking. She had persistent fever, asthenia, and dysphagia. The medical investigations for fever were not conclusive. Three weeks later she returned with dyspnea, left pleural effusion, fever, and aphagia. A CT scan, performed for suspicion of a pulmonary embolism, revealed a spontaneous aortic rupture with a periaortic hematoma compressing the esophagus and the left atrium (Figure 2).

The patient was immediately transferred to our unit, where we performed an endovascular covering of the aortic rupture by deploying a 25-mm-diameter Talent endoluminal stent graft. Because the right femoral artery was too small, we proceeded through the right common iliac artery. The procedure went well, with no leaking or adverse medullary effect. On day 7, the patient had a hematemesis. An upper esophageal fiberoptic endoscopy showed an aortoesophageal fistula $30 \mathrm{~cm}$ from the dental arch and an esophageal ulcer covered with clots (Figure 3). The injected CT scan revealed no leak, no stent migration, and no kinking and showed no regression of the periaortic hematoma (Figure 2). The aortoesophageal fistula was managed with esophagectomy with bilateral exclusion by means of right thoracotomy, cervical esophagostomy, and gastrostomy. The patient had a promising outcome in the early postoperative period but developed sepsis and died 2 months later.

\section{Discussion}

Aortoesophageal fistula is a well-known complication of descending thoracic aortic grafting. ${ }^{3}$ Cases after esophageal ${ }^{4,5}$ and bronchial $^{6}$ stenting have also been described. To the best of our knowledge, no case of aortoesophageal fistula after endovascular repair of descending thoracic aortic diseases has been reported to date. We report 2 cases of patients with aphagia at the time of 

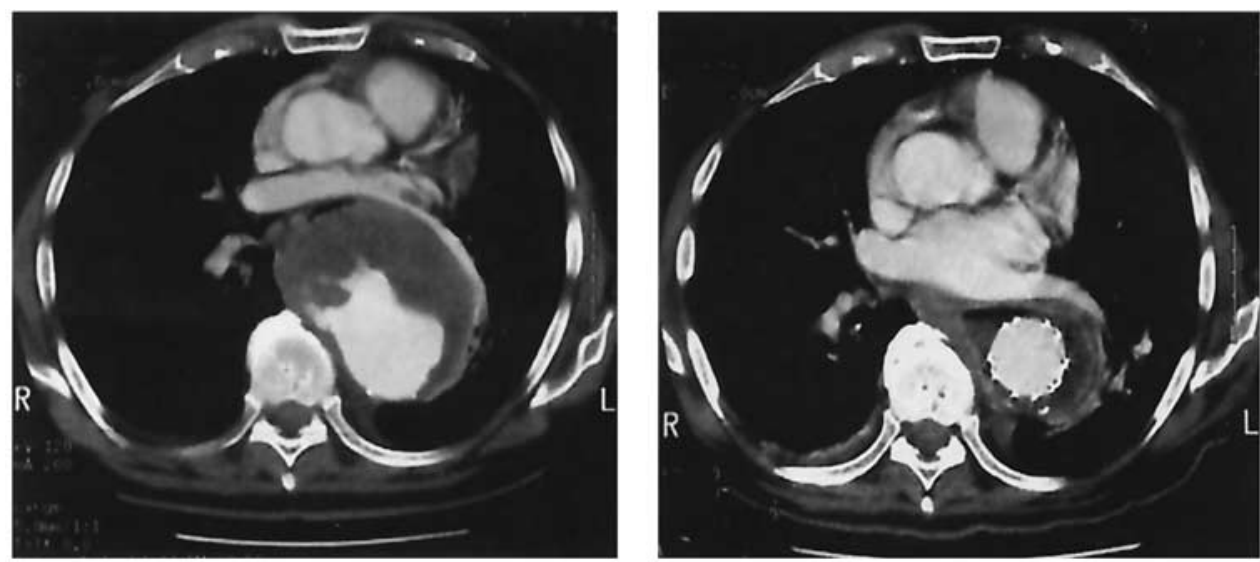

Figure 1. Patient 1: left, CT scan before aortic stenting; right, CT scan 45 days later, when the aortoesophageal fistula was diagnosed. Note the retraction of the aneurysm from 94 to $60 \mathrm{~mm}$ in diameter.
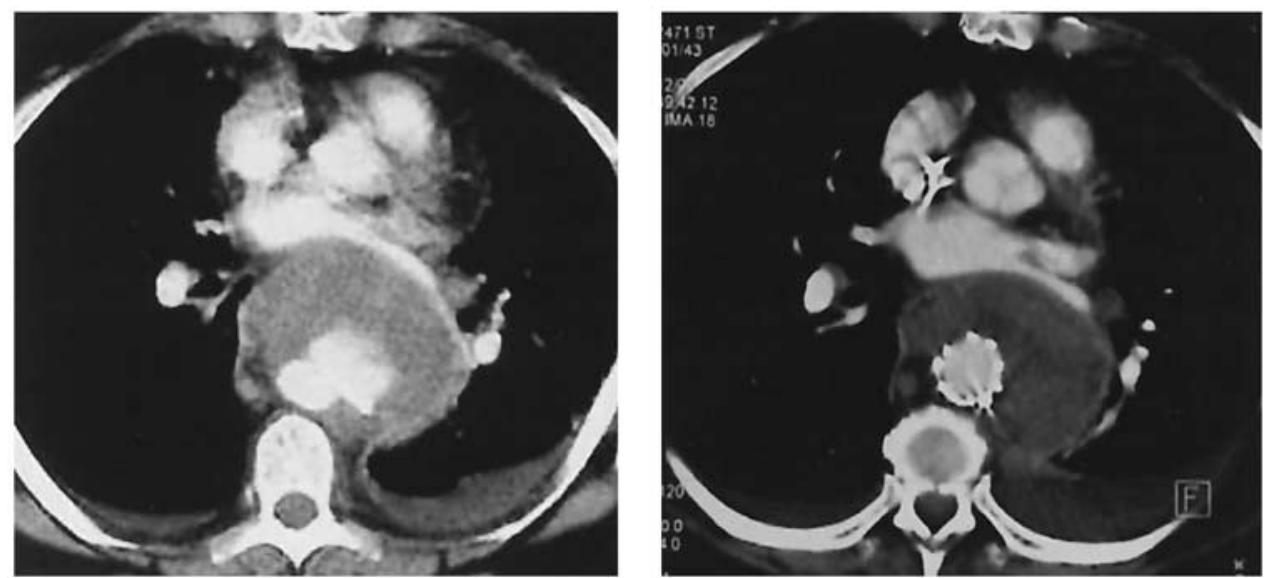

Figure 2. Patient 2: left, CT scan before aortic stenting; right, CT scan 7 days later, when the aortoesophageal fistula was diagnosed. Note the unchanged diameter of the periaortic hematoma.
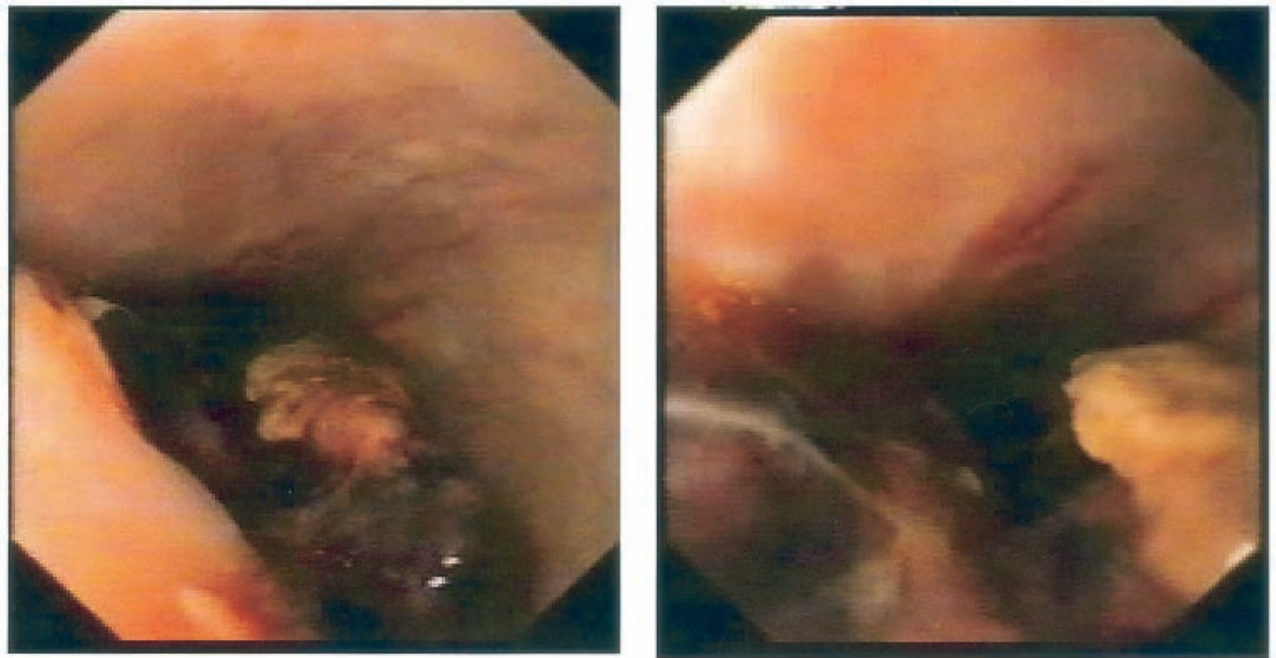

Figure 3. Fibroscopic views of the aortoesophageal fistula in patient 2. 
diagnosis, evidenced by the compression of the esophagus by the aneurysm or the hematoma and confirmed by the CT scan.

The first patient had an upper esophageal fiberoptic endoscopy with biopsies before discovery of the aneurysm. Obviously, the biopsies might have facilitated the disclosure of the fistula, but the retraction of the aneurysm after exclusion worsened the fistula at the least. This hypothesis is supported by the 45-day interval between the operation and the apparition of the fistula.

The second patient had no upper esophageal fiberoptic endoscopy. In this case the fistula was most likely present at the time of the diagnosis. This is supported by 2 facts: (1) the short interval between aortic stenting and diagnosis of the fistula prevented retraction of the hematoma, and (2) the patient described having a rotting taste before being hospitalized. However, compression of the hematoma is likely to have worsened the fistula.

The development of the fistula cannot be linked to the specific stent graft used. In both cases the iterative injected CT scans showed no feature that could incriminate the device, and in particular, there was no evidence of aortic free wall rupture.

These 2 cases highlight the care one should take in proposing endovascular stenting in patients with dysphagia or aphagia. Compared with classic surgical intervention, endovascular stenting does not remove the periaortic hematoma or the intra-aneurysmal thrombosis, and hence the esophagus remains compressed after the procedure, thus allowing the ischemic lesions of the esophagus to develop. Moreover, this fragile ischemic zone is subject to mechanical aggression caused by the retraction of the aneurysm or the hematoma. The result is that a small fistula, which can recover with the removal of the compression, is likely to be worsened and enlarged by leaving compression to do its work.

We are grateful to Nancy Richardson-Peuteuil for her editorial assistance.

\section{References}

1. Dake MD, Miller DC, Mitchell RS, et al. The "first generation" of endovascular stent-grafts for patients with aneurysms of the descending thoracic aorta. J Thorac Cardiovasc Surg. 1998;116:689-703.

2. Reardon MJ, Brewer RJ, Le Maire SA, et al. Surgical management of primary aortoesophageal fistula secondary to thoracic aneurysm. Ann Thorac Surg. 2000;69:967-70.

3. Wickstrom PH, Streitz JM, Erickson RV, et al. Repair of aortoesophageal fistula after aortic grafting. Ann Thorac Surg. 1997;64:253-5.

4. Grundy A, Glees JP. Aorto-oesophageal fistula: a complication of oesophageal stenting. Br J Radiol. 1997;70:846-9.

5. Allgaier HP, Schwacha H, Technau K, et al. Fatal esophagoaortic fistula after placement of a self-expanding metal stent in a patient with esophageal carcinoma. N Engl J Med. 1997;337:1778.

6. Nouraei SM, Pillay T, Hilton CJ. Emergency management of aortobronchial fistula after implantation of a self-expanding bronchial stent. Eur J Cardiothorac Surg. 2001;20:642-4. 